Bangladesh J. Bot. 37(1): 27-32, 2008 (June)

\title{
RELATIONSHIPS BETWEEN SEED YIELD AND YIELD COMPONENTS IN NARBON BEAN (VICIA NARBONENSIS L.) BY PATH ANALYSIS
}

\author{
Mevlüt Türk ${ }^{*}$, Necmettin Çelík ${ }^{1}$, Gamze Bayram ${ }^{1}$ and Emine Budakli ${ }^{1}$ \\ Department of Field Crops, Faculty of Agriculture, \\ Süleyman Demirel University, Isparta-Turkey
}

Key words: Biological yield, Correlation coefficient, Harvest index, Stepwise multiple regression

\begin{abstract}
Results of correlation analysis indicated that seed yield in narbon bean (Vicia narbonensis L.) was correlated positively with harvest index, biological yield, weight, number of seed and number of pod per plant and also plant height and number of plant per $\mathrm{m}^{2}$. Path coefficient analyses revealed that harvest index and biological yield had higher positive direct effects on seed yield than other variables. Stepwise multiple regression analysis showed that $95.1 \%$ of total variation in seed yield could be explained by the variation in harvest index, biological yield and plant height. Results suggest that harvest index and biological yield are primary selection criteria for improving seed yield in narbon bean.
\end{abstract}

\section{Introduction}

Narbon bean (Vicia narbonensis L.) is a winter legume with erect stems that make it an easy crop for harvesting. A forage and grain legume plant of Mediterranean origin, it is of particular interest for neutral to alkaline soils in lower rainfall districts, where its erect habit and strong tap root and stem are attractive features in overcoming some of the major limitations with field peas (Jaques et al. 1994).

Path coefficient and correlation analyses are being widely used in many crop species by plant breeders to understand the nature of complex interrelationships among traits and to identify the sources of variation in yield. The knowledge can be utilized to develop selection criteria to improve seed yield with agricultural practices (Gravois and McNew 1993, Board et al. 1997, Samonte et al. 1998, Finne et al. 2000, Sinebo 2002).

A number of investigators (Yücel 2004, Çakmakçı et al. 2003, Sindhu et al. 1985) reported that the direct effects of biological yield and harvest index on seed yield were greater than other yield components.

As yet no similar report is available on narbon bean. The present study was undertaken to determine characters affecting seed yield in narbon bean genotypes using simple correlation, path and stepwise multiple regression analyses.

\section{Materials and Methods}

This experiment was conducted at the Agricultural Research and Experiment Station of Agriculture Faculty, Uludag University, Turkey during 2000 - 2002. Fifteen lines of narbon bean (Vicia narbonensis L.) provided by International Center for Agricultural Research in the Dry Areas (ICARDA) were used as genetic materials. The experimental soil was clayey, non saline, poor in lime and organic matter, rich in potassium and a neutral $\mathrm{pH}$. Average temperature, relative humidity and precipitation were $12.9^{\circ} \mathrm{C}$ and $292.2 \mathrm{~mm}$ in $2000-2001$ and $11.3^{\circ} \mathrm{C}$ and $754.6 \mathrm{~mm}$ in $2001-2002$, respectively.

*Corresponding author. E-mail: mturk72@ziraat.sdu.edu.tr ${ }^{1}$ Department of Field Crops, Faculty of Agriculture, Uludag University, Bursa-Turkey. 
The experiment was carried out with ramdomized complete block design and with three replications. Sowing was made by hand in $4 \mathrm{~m}$ long rows with $0.3 \mathrm{~m}$ row spacings on November 10, 2000 and November 26, 2001. Plots were fertilized with $100 \mathrm{~kg} / \mathrm{ha}$ compost fertilizer (20-200 ). Harvest was made on June 7, 2001 and June 18, 2002. Measurements and observations of the characters were done on randomly chosen ten plants, from the mid-row of each plot. The parameters observed and measured were days to flowering (DF), plant height $(\mathrm{PH})$, number of plant per $\mathrm{m}^{2}\left(\mathrm{NP} / \mathrm{m}^{2}\right)$, number of pod per plant (PN/P), number of seed per plant $(\mathrm{SN} / \mathrm{P})$, weight of seed per plant (SW/P), thousand seed weight (TSW), biological yield (BY), harvest index (HI) and seed yield (SY). Days to flowering was time from sowing to $50 \%$ flowering. Plant height and number of plant per $\mathrm{m}^{2}$ were measured before harvest and other characters were measured at or after harvest.

The two years data were combined and subjected to variance analyses. The simple phenotypic correlation coefficient among all the observed components were first calculated by the SAS statistical program and then they were separated into direct and indirect effects via path coefficient analyses as suggested by Dofing and Knight (1992) and Rodriguez et al. (2001). Stepwise multiple regression analysis was carried out using SAS statistical program (SAS Institute 1998).

\section{Results and Discussion}

Simple correlation coefficient calculated between the seed yield and other variables are given in Table 1. Seed yield was positively and highly correlated with $\mathrm{PH}, \mathrm{NP} / \mathrm{m}^{2}, \mathrm{PN} / \mathrm{P}, \mathrm{SN} / \mathrm{P}, \mathrm{SW} / \mathrm{P}$, BY and HI $\left(r=0.369^{* *}, r=0.254^{*}, r=0.538^{* *}, r=0.445^{* *}, r=0.531^{* *}, r=0.323^{* *}, r=0.769^{* *}\right.$, respectively), but it was negatively correlated with days to flowering $(\mathrm{r}=-0.17)$. Days to flowering gave negative correlation with all other components except PH and HI. These results

Table 1. Correlation coefficients among characters in narbon bean (average of two years).

\begin{tabular}{|c|c|c|c|c|c|c|c|c|c|c|}
\hline & SY & $\mathrm{DF}$ & $\mathrm{PH}$ & $\mathrm{NP} / \mathrm{m}^{2}$ & $\mathrm{PN} / \mathrm{P}$ & $\mathrm{SN} / \mathrm{P}$ & $\mathrm{SW} / \mathrm{P}$ & TSW & BY & $\mathrm{HI}$ \\
\hline SY & 1.000 & $-0.17^{\mathrm{ns}}$ & $0.369^{* *}$ & $0.254^{*}$ & $0.538^{* *}$ & $0.445^{* *}$ & $0.531^{* *}$ & $0.201^{\mathrm{ns}}$ & $0.323^{* *}$ & $0.769^{* *}$ \\
\hline DF & & 1.000 & $0.025^{\mathrm{ns}}$ & $-0.114^{\mathrm{ns}}$ & $-0.104^{\mathrm{ns}}$ & $-0.084^{\mathrm{ns}}$ & $-0.113^{\mathrm{ns}}$ & $-0.131^{\mathrm{ns}}$ & $-0.173^{\mathrm{ns}}$ & $0.128^{\mathrm{ns}}$ \\
\hline PH & & & 1.000 & $0.624^{* *}$ & $0.697^{* *}$ & $0.501^{* *}$ & $0.312^{* *}$ & $-0.360^{* *}$ & $0.049^{\mathrm{ns}}$ & $0.280^{* *}$ \\
\hline $\mathrm{NP} / \mathrm{m}^{2}$ & & & & 1.000 & $0.444^{* *}$ & $0.270^{* *}$ & $0.271^{* *}$ & $-0.175^{\mathrm{ns}}$ & $-0.103^{\mathrm{ns}}$ & $0.268^{* *}$ \\
\hline $\mathrm{PN} / \mathrm{P}$ & & & & & 1.000 & $0.894^{* *}$ & $0.764^{* *}$ & $-0.154^{\mathrm{ns}}$ & $0.160^{\mathrm{ns}}$ & $0.414^{* *}$ \\
\hline $\mathrm{SN} / \mathrm{P}$ & & & & & & 1.000 & $0.810^{* *}$ & $-0.206^{* *}$ & $0.141^{\mathrm{ns}}$ & $0.355^{* *}$ \\
\hline $\mathrm{SW} / \mathrm{P}$ & & & & & & & 1.000 & $0.318^{* *}$ & $0.157^{\mathrm{ns}}$ & $0.461^{* *}$ \\
\hline TSW & & & & & & & & 1.000 & $0.144^{\mathrm{ns}}$ & $0.149^{\mathrm{ns}}$ \\
\hline BY & & & & & & & & & 1.000 & $-0.314^{* *}$ \\
\hline HI & & & & & & & & & & 1.000 \\
\hline
\end{tabular}

DF: Days to flowering, PH: Plant height,NP/ $\mathrm{m}^{2}$ : Number of plant per $\mathrm{m}^{2}$,PN/P: Pod number per plant, SN/P: Seed number per plant, SW/P: Seed weight per plant, TSW: Thousand seed weight, BY: Biological yield, HI: Harvest index and SY: Seed yield. ${ }^{*} \mathrm{p}<0.05,{ }^{* *} \mathrm{p}<0.01$. ns: Non significant.

were consistent with the findings of some other. Çakmakçı et al. (2003) observed positive and significant correlations between SY and BY $\left(\mathrm{r}=0.810^{* *}\right)$, HI $\quad\left(\mathrm{r}=0.423^{* *}\right)$, PH $\left(\mathrm{r}=0.296^{* *}\right)$, $\mathrm{SN} / \mathrm{P}\left(\mathrm{r}=0.486^{* *}\right), \mathrm{PN} / \mathrm{P}\left(\mathrm{r}=0.418^{* *}\right)$ in common vetch. Similar results were reported by others (Büyükburç and Iptaş 2001, Yücel 2004, Çakmakçı and Açıkgöz 1994).

Correlation coefficient analyses usually show relationships among independent traits and the degree of linear relation between these characters. Consequently, these interrelationships with 
regards to sign and magnitude were found to be different when path analyses were performed. The relationships determined by path analysis among the characteristics are shown in Table 2.

Path coefficient analysis (Table 2) on identified harvest index (0.9579) showed greatest direct effect on seed yield, with biological yield (0.6181) having a large secondary effect. Other components had low direct effect on seed yield. Weight of seed per plant showed a large negative indirect effect via harvest index on seed yield.

The findings of the present investigation are in agreement with the results of Çakmakçı et al. (2003) and Albayrak and Töngel (2006) who observed that direct effects of harvest index and biological yield on seed yield were significant in common vetch.

Analysis of results showed that the ratio of direct effect of harvest index on seed yield was $73.46 \%$ and indirect effect of harvest index via other variables was $26.54 \%$. The ratio of direct effects of biological yield on seed yield was $63.02 \%$ and ratio of indirect effects of biological yield via other variables was $36.98 \%$ (Table 2). These results were consistent with the findings of some other reports dealt with path analyses. As found in this study, Cousin et al. (1985) found that harvest index was the most important factor influencing the seed yield in peas. Shrivastava et al. (2001) also found that biological yield and harvest index were important traits affecting the seed yield. The direct effects of plant height $(0.0384)$ and number of plant per $\mathrm{m}^{2}(0.0401)$ on seed yield were found to be non-significant indicating that these traits should not be considered as the choice of selection characters for seed yield improvement studies. On the other hand, the direct effects of days to flowering and weight of seed per plant on seed yield were negative and except biological yield, indirect effects of all dependent variables via harvest index were found positive and high (Table 2).

Results of the present study also indicated that there was negative indirect effects of biological yield via harvest index on seed yield whereas there were positive and significant correlation between biological yield and seed yield $\left(0.323^{* *}\right)$. This meant that correlation between seed- and biological yield would have been high had it not been for the large negative indirect effect of harvest index via biological yield on seed yield. Conversely, the correlation between seed yield and biological yield was reduced by negative indirect effect of harvest index. Similar result was reported by Çakmakçı et al. (2003).

Findings of this investigation indicated that the components showing the highest correlations with seed yield also had the largest direct effect on yield. For instance, correlation coefficient between seed yield and harvest index was 0.769 and path coefficient value was 0.9579 (Table 2).

Results obtained also indicated that correlation coefficient- and path analysis were not always in agreement and magnitude of the correlation coefficients were low. For example, correlation coefficient between seed yield and weight of seeds per plant was 0.531 whereas path coefficient of the relation was -0.1510 . If the correlation coefficient is positive, but the direct effect is negative or negligible, the indirect effects seem to be reason of correlation. In such situations, the indirect causal factors must be considered simultaneously (Singh and Chaudhary 1977). In present study, weight of seeds per plant showed a large positive indirect effect via harvest index (0.4416 and $52.98 \%$ ).

These results indicated that correlation coefficient analyses should not be considered as the only method to determine the relationship between traits in plant breeding studies, instead both correlation and path coefficient analyses should be used together. 
Table 2. Phenotypic path coefficient showing direct and indirect effects of different components on seed yield (averages of two years).

\begin{tabular}{|c|c|c|c|c|c|}
\hline & Path coef. & $\%$ & & Path coef. & $\%$ \\
\hline DF vs seed yield & $\mathrm{r}=-0.170^{\mathrm{ns}^{*}}$ & & SW/P vs seed yield & $\mathrm{r}=0.531^{* *}$ & \\
\hline Direct effect & -0.0269 & 8.99 & Direct effect & -0.1510 & 18.12 \\
\hline Indirect effect via $\mathrm{PH}$ & 0.0010 & 0.32 & Indirect effect via DF & 0.0031 & 0.37 \\
\hline Indirect effect via $\mathrm{NP} / \mathrm{m}^{2}$ & -0.0046 & 1.53 & Indirect effect via $\mathrm{PH}$ & 0.0120 & 1.44 \\
\hline Indirect effect via PN/P & -0.0066 & 2.20 & Indirect effect via $\mathrm{NP} / \mathrm{m}^{2}$ & 0.0109 & 1.31 \\
\hline Indirect effect via SN/P & -0.0053 & 1.79 & Indirect effect via PN/P & 0.0485 & 5.81 \\
\hline Indirect effect via SW/P & 0.0171 & 5.73 & Indirect effect via SN/P & 0.0513 & 6.16 \\
\hline Indirect effect via TSW & -0.0075 & 2.51 & Indirect effect via TSW & 0.0182 & 2.19 \\
\hline Indirect effect via BY & -0.1071 & 35.80 & Indirect effect via BY & 0.0969 & 11.63 \\
\hline Indirect effect via HI & 0.1231 & 41.13 & Indirect effect via HI & 0.4416 & 52.98 \\
\hline PH vs seed yield & $r=-0.369^{* *}$ & & TSW vs seed yield & $\mathrm{r}=0.201^{\mathrm{ns}}$ & \\
\hline Direct effect & 0.0384 & 7.59 & Direct effect & 0.0574 & 14.94 \\
\hline Indirect effect via DF & -0.0007 & 0.13 & Indirect effect via DF & 0.0035 & 0.92 \\
\hline Indirect effect via NP/m² & 0.0251 & 4.95 & Indirect effect via $\mathrm{PH}$ & -0.0138 & 3.60 \\
\hline Indirect effect via PN/P & 0.0442 & 8.73 & Indirect effect via $\mathrm{NP} / \mathrm{m}^{2}$ & -0.0070 & 1.82 \\
\hline Indirect effect via SN/P & 0.0318 & 6.28 & Indirect effect via PN/P & -0.0097 & 2.54 \\
\hline Indirect effect via SW/P & -0.0471 & 9.32 & Indirect effect via $\mathrm{SN} / \mathrm{P}$ & -0.0130 & 3.40 \\
\hline Indirect effect via TSW & -0.0207 & 4.09 & Indirect effect via SW/P & -0.0480 & 12.48 \\
\hline Indirect effect via BY & 0.0303 & 5.98 & Indirect effect via BY & 0.0892 & 23.21 \\
\hline Indirect effect via HI & 0.2679 & 52.94 & Indirect effect via HI & 0.1426 & 37.11 \\
\hline $\mathrm{NP} / \mathrm{m}^{2}$ vs seed yield & $\mathrm{r}=-0.254^{*}$ & & BY vs seed yield & $\mathrm{r}=0.323^{* *}$ & \\
\hline Direct effect & 0.0401 & 8.31 & Direct effect & 0.6181 & 63.02 \\
\hline Indirect effect via DF & 0.0031 & 0.64 & Indirect effect via DF & 0.0047 & 0.48 \\
\hline Indirect effect via $\mathrm{PH}$ & 0.0240 & 4.96 & Indirect effect via $\mathrm{PH}$ & 0.0019 & 0.19 \\
\hline Indirect effect via PN/P & 0.0281 & 5.82 & Indirect effect via $\mathrm{NP} / \mathrm{m}^{2}$ & -0.0041 & 0.42 \\
\hline Indirect effect via SN/P & 0.0171 & 3.54 & Indirect effect via PN/P & 0.0101 & 1.03 \\
\hline Indirect effect via SW/P & -0.0409 & 8.47 & Indirect effect via SN/P & 0.0089 & 0.91 \\
\hline Indirect effect via TSW & -0.0100 & 2.08 & Indirect effect via SW/P & -0.0237 & 2.42 \\
\hline Indirect effect via BY & -0.0634 & 13.2 & Indirect effect via TSW & 0.0083 & 0.85 \\
\hline Indirect effect via HI & 0.2564 & 53.06 & Indirect effect via HI & -0.3010 & 30.69 \\
\hline PN/P vs seed yield & $\mathrm{r}=0.538^{* *}$ & & HI vs seed yield & $\mathrm{r}=0.769^{* *}$ & \\
\hline Direct effect & 0.0634 & 8.06 & Direct effect & 0.9579 & 73.46 \\
\hline Indirect effect via DF & 0.0028 & 0.35 & Indirect effect via DF & -0.0035 & 0.27 \\
\hline Indirect effect via $\mathrm{PH}$ & 0.0268 & 3.40 & Indirect effect via $\mathrm{PH}$ & 0.0107 & 0.82 \\
\hline Indirect effect via NP/m $/ \mathrm{m}^{2}$ & 0.0178 & 2.26 & Indirect effect via $\mathrm{NP} / \mathrm{m}^{2}$ & 0.0107 & 0.82 \\
\hline Indirect effect via SN/P & 0.0566 & 7.19 & Indirect effect via PN/P & 0.0262 & 2.01 \\
\hline Indirect effect via SW/P & -0.1154 & 14.67 & Indirect effect via SN/P & 0.0225 & 1.73 \\
\hline Indirect effect via TSW & -0.0088 & 1.12 & Indirect effect via SW/P & -0.0696 & 5.34 \\
\hline Indirect effect via BY & 0.0988 & 12.55 & Indirect effect via TSW & 0.0086 & 0.66 \\
\hline Indirect effect via HI & 0.3965 & 50.39 & Indirect effect via BY & -0.1942 & 14.89 \\
\hline SN/P vs seed yield & $\mathrm{r}=0.445^{* *}$ & & & & \\
\hline Direct effect & 0.0633 & 8.88 & & & \\
\hline Indirect effect via DF & 0.0023 & 0.32 & & & \\
\hline Indirect effect via $\mathrm{PH}$ & 0.0193 & 2.70 & & & \\
\hline Indirect effect via $\mathrm{NP} / \mathrm{m}^{2}$ & 0.0108 & 1.52 & & & \\
\hline Indirect effect via PN/P & 0.0566 & 7.94 & & & \\
\hline Indirect effect via SW/P & -0.1223 & 17.14 & & & \\
\hline Indirect effect via TSW & -0.0118 & 1.66 & & & \\
\hline Indirect effect via BY & 0.0871 & 12.20 & & & \\
\hline Indirect effect via HI & 0.3401 & 47.65 & & & \\
\hline
\end{tabular}

ns: non-significant. ${ }^{*}, *$ : significant at $\mathrm{p}<0.05$ and $\mathrm{p}<0.01$ respectively. 
Stepwise multiple regression analysis showed that $95.1 \%$ of total variation in seed yield could be explained by the variation in harvest index, biological yield and plant height (Table 3 ). The present results are consistent with that of Albayrak and Töngel (2006).

Table 3. Summary of stepwise multiple regression analysis of seed yield and seed yield components in narbon bean.

\begin{tabular}{lc}
\hline Regression equations & Coefficient of determination \\
\hline $\mathrm{SY}=49.407+6.781 \mathrm{HI}$ & 0.592 \\
$\mathrm{SY}=-202.796+8.512 \mathrm{HI}+0.234 \mathrm{BY}$ & 0.946 \\
$\mathrm{SY}=-208.333+8.299 \mathrm{HI}+0.230 \mathrm{BY}+0.164 \mathrm{PH}$ & 0.951 \\
\hline
\end{tabular}

SY: Seed yield, HI: Harvest index, BY: Biological yield, PH: Plant height.

As a result determining correlation coefficients among components affecting seed yield in narbon bean was insufficient to determine selection criteria for the seed yield improvement studies. Although, the path coefficient analysis of variables showed that there were direct and indirect effects of some other traits on the seed yield. Results obtained during this investigation indicated that narbon bean breeding studies should focus on harvest index, biological yield and number of seeds per plant for improvement studies of high seed yielding varieties.

\section{References}

Albayrak, S. and Ö. Töngel. 2006. Path analyses of yield and yield-related traits of common vetch (Vicia sativa L.) under different rainfall conditions. J. Agric. Faculty Ondokuzmayis Univ. 21: 27-32.

Board, J.E., M.S. Kang and B.G. Harville. 1997. Path analyses identify indirect selection criteria for yield of late planted soybean. Crop Sci. 37:879-884.

Büyükburç, U and S. Iptaş. 2001. The yield and yield components of some Narbon Vetch (Vicia narbonensis L) lines in Tokat ecological conditions. Turkish J. Agric. and Forestry. 25: 79-88.

Cousin, R., A. Massager and A. Vingere. 1985. Breeding for yield in combining peas. The Pea Crops. P.H. Hebblethwaite, M.C. Heath and T.C.K. Dawkins (Eds.). Butterworths. p. 115-129.

Çakmakçı, S. and E. Açıkgöz. 1994. Components of seed and straw yield in common vetch (Vicia sativa L.). Plant Breed. 113: 71-74.

Çakmakçı, S., B. Aydınoğlu and M. Karaca. 2003. Determinig relationships among yield and yield components using correlation and path analysis in summer sown common vetch (Vicia sativa L.) genotypes. Pakistan J. Bot. 35(3): 387-400.

Dofing, S.M. and C.W. Knight. 1992. Alternative model for path analysis of small-grain yield. Crop Sci. 32: 487-489.

Finne, M.A., O.A. Rognli and I. Schjelderup. 2000. Genetic variation in a Norwegian germplasm collection of white clover (Trifolium repens L.):3.Correlation and path coefficient analyses of agronomic characters. Euphytica 112: 57-68.

Gravois, K.A. and R.W. McNew. 1993. Genetic relationships among and selection for rice yield and yield components. Crop Sci. $37: 879-884$.

Jaques S., R.M. Dixon, J.H.G. Holmes. 1994. Narbon beans and field peas as supplements for sheep, Small Rumin. Res. 15: 39-43.

Rodriguez, D. Jasso de., J.L. Angulo-Sanchez and R. Rodriguez-Garcia. 2001. Correlation and path coefficient analyses of the agronomic trait of a native population of guayule plants. Industrial Crops and Products. 14:93-103.

Samonte, S.O., L.T. Wilson and M. McClung. 1998. Path analyses of yield and yield-related traits of fifteen diverse rice genotypes. Crop Sci. 38: 1130-1136.

SAS Institute. 1998. INC SAS/STAT users' guide release 7, Cary, NC, USA. 
Shrivastava, M.K., R.S. Shukla and P.K. Jain. 2001. Path coefficient analysis in diverse genotype of soybean (Glycine max (L.) Merill). Adv. Plant Sci. 14: 47-51.

Sindhu, J.S., O.P. Singh and K.P. Singh. 1985. Component analysis of the factors determining grain yield in faba bean (Vicia faba L.). FABIS-Newsletter ICARDA. Faba bean Information Service. 13: 3-5.

Sinebo, W. 2002. Yield relationships of barleys grown in a tropical highland environment. Crop Sci. 42: 428437.

Singh, K.B. and B.D. Chaudhary. 1977. Biometrical methods in quantitative genetic analysis. Kalyani publishers. New Delhi, pp. 304.

Yücel, C. 2004. Correlation and path coefficient analyses of seed yield components in the narbon bean (Vicia narbonensis L.). Turkish J. Agric. \& Forestry. 28: 371-376.

(Manuscript received on 30 July, 2006; revised on 29 May, 2007) 